\title{
Application Research for DP Enhanced Notation
}

\author{
HU Xiaolin
}

Marine Design \& Research Institute of China, Shanghai 200011, China

\begin{abstract}
DP enhanced notations are the new technical application on traditional DP system in order to adapt to higher requirements on offshore unit. But they are very complicated to apply. This article introduces the general of DP enhanced notations. At the same time, it provides a case, based on $145 \mathrm{~m}$ DSV built in a yard located at Shanghai, China. This case shows main settings for control systems and auxiliary systems of DNV "DYNPOS-ER". DP analysis and FMEA reports show all these setting can fulfill the requirements of Rules and diving operations.
\end{abstract}

Key words: Application, research, DP enhanced notation, DYNPOS-ER.

\section{Introduction}

The dynamic positioning system has been more and more widely applied on offshore projects, such as Drilling vessel, DSV, FPU/FPSO, accommodation vessel, crane vessel, shuttle tanker, pipelay vessel, ROV support vessel, AHTS etc. Additionally, two-vessel operation is also applied. It improves vessel's capability and operating reliability extremely.

Along with technology development, working condition requirement etc., traditional DP class cannot completely fulfill diversified needs of the vessel operation little by little. Some classes recommended new DP Class notations to enhance their traditional DP classifications in order to fulfill these market needs. For example, ABS provided enhanced notations, "EHS-P", "EHS-C" and "EHS-F" for her traditional DP classifications, DPS-2 and DPS-3; DNV also provided enhanced notations, "DYNPOS-E" and "DYNPOS-ER" for her traditional DP classifications, DYNPOS-AUTR/DPS 2 and DYNPOS-AUTRO/DPS 3. DNV-GL inherits related contents from DNV but the notation marks have been changed to DYNPOS(E) and DYNPOS(ER) which are relative for DYNPOS(AUTR) and DYNPOS(AUTRO).

The followings will introduce the application for

Corresponding author: HU Xiaolin, bachelor, senior engineer, research field: machinery of offshore unit.
DNV enhanced notation, "DYNPOS-ER", on vessel as an example. This vessel is operated for diving support and being built in a yard located at Shanghai, China.

\section{General}

\subsection{Vessel's General}

The vessel is designed as a multi-role offshore construction and diving support vessel with the flexibility for operational modes including diving support, ROV Support and offshore construction. Consideration is made for future operational modes including Pipe/Cable laying, well intervention, wellhead operations and drilling. The vessel shall be built for world-wide sub-sea operations including operation in coastal water of any state.

The principal particulars are as followings:

$\begin{array}{ll}\text { length over all: } & \sim 145.9 \mathrm{~m} \\ \text { length between perp.: } & \sim 133.8 \mathrm{~m} \\ \text { breadth: } & 27 \mathrm{~m} \\ \text { depth to main deck: } & 11.3 \mathrm{~m} \\ \text { depth to tween deck: } & 6.2 \mathrm{~m} \\ \text { max. draft ocv: } & 7.65 \mathrm{~m} \\ \text { max. draft dsv: } & 6.85 \mathrm{~m} \\ \text { scantling draft } & 7.65 \mathrm{~m} \\ \text { pob: } & 200 \text { persons } \\ \text { class: } & \text { DNV }\end{array}$

The class notations related to DP systems are DYNPOS-AUTRO and DYNPOS-ER. 


\subsection{DYNPOS-ER}

\section{What is DYNPOS-ER?}

In DNV Rules, Part 6 Chapter 26, DYNPOS-ER means "Enhanced Reliability and Separation". It is a dynamic positioning system with redundancy and higher degree of flexibility based on utilization of stand-by units and/or change-over mechanisms. It meets intentions comparable to or exceeds IMO equipment class 2 and 3 but has no direct relation to IMO MSC/Cir. 645 and can give vessel with flexibility, reliability, fuel economy and benefit of environment. Generally, it is advised to be used in combination with a traditional DP notation. If so, the vessel will have two class notations for DP but still can be operated as a traditional DP vessel when required. And, no additional surveys will be required.

DYNPOS-ER rules are based on principles and philosophies which are adapted to, and make it possible to better utilize the latest technology within power generation, power distribution, thruster technology and advanced integrated control systems in order to allow for flexible and efficient operation of the power and thruster plant.

For example, a vessel arranges four (4) E/Rs, each E/R has two (2) generator sets and each E/R corresponds to one (1) thruster room with two (2) thrusters. If a traditional DP-3 notation (AUTRO) applied, one (1) set of auxiliary system is arranged for each E/R, A-60 bulkhead is needed for each E/R, A-60 \& watertight bulkhead is needed for each thruster room and Open Bustie should be set between MSBs. When single failure occurs, such as auxiliary system faults or E/R lost, relative thruster room will be lost. That means one forth of thruster capacity lost. Furthermore, minimum four (4) generator sets must be in running condition at low load. If DYNPOS-ER notation applied, one (1) set of auxiliary system is arranged for each generator set, A-60 bulkhead is needed for each E/R, watertight bulkhead is needed for each thruster room and closed bustie can be set between MSBs. If one (1) set of auxiliary system fault, relative generator set will be lost but no thruster will be lost because of closed bustie. If one E/R lost, remained power supply can maintain seven thrusters. Only $12.5 \%$ thruster capacity will be lost. Furthermore, minimum two (2) generator sets must be in running condition at low load.

\section{Basic in DP Design Philosophy}

It is very important that the technical operational philosophy for the vessel systems should be agreed between the owner and yard, and informed to Class as basis for the approval. Some basic info in DP Design Philosophy is listed as followings:

\subsection{DP Zone}

The DP zones on this vessel are divided into three (3) parts (ZONE 1, ZONE 2, ZONE 3) as per DYNPOS-ER requirements. The A-60 separation is carried out strictly between these zones. The DP ZONE 1 and 2 will contain the equipments in Table 1 and DP

Table 1 Equipments in DP ZONE 1 \& 2.

\begin{tabular}{llll}
\hline \multicolumn{1}{c}{ DP ZONE 1 } & \multicolumn{2}{c}{ DP ZONE 2 } & Quantity \\
\hline Equip. name & Quantity & Equip. name & One (1) \\
\hline Main HV Switchboard (No. 1) & One (1) & Main HV Switchboard (No. 2) & Three (3) \\
Generator Sets (G1, G2, G3) & Three (3) & Generator Sets (G4, G5, G6) & One (1) \\
Azimuth Thruster Aft (T4) & One (1) & Azimuth Thruster Aft (T6) & One (1) \\
Bow Tunnel Thruster Fwd (T1) & One (1) & Bow Retractable Thruster(T3) & One (1) \\
Ship 440V Switchboard (No. 1) & One (1) & Ship 440V Switchboard (No. 2) & One (1) \\
Crane 690V Switchboard (No. 1) & One (1) & Crane 690V Switchboard (No. 2) & One (1) \\
Dive 440V Switchboard (No. 1) & One (1) & Dive 440V Switchboard (No. 2) & One (1) \\
Deck \& ROV 440V Switchboard (No. 1) & One (1) & Deck \& ROV 440V Switchboard (No. 2) & One (1) \\
Port Side Instrumentation Room & One (1) & Starboard Side Instrumentation Room & One (1) \\
Port Side Vertical Cable Duct & One (1) & Port Side Vertical Cable Duct & \\
\hline
\end{tabular}


ZONE 3 will contain one set of Bow Tunnel Thruster (T2) and one set of Azimuth Thruster Aft (T5). Two redundant group zones are set in DP zones 1 \& 2 respectively. The equipments in DP ZONE 3 belong to Dual In-Feed equipment. These Dual In-Feed equipments will be considered as two (2) separate redundancy groups.

The detail arrangement is showed in Fig. 1.

\subsection{WCFDI}

By employing the Dual In-Feed concept in all operational modes, the WCFDI (Worst Case Failure Design Intent) of the vessel will be the loss of a single HV Switchboard. Upon loss of either HV Switchboard the following machineries/equipments within the same associated redundant group will also be lost. Detail technical design is listed in Table 2.

In either of the worst case failure modes in Table 2, the vessel will be still under complete control of the DP system with the these machinery items: one (1) Main
Switchboard, three (3) Generator Sets, two (2) Azimuth Thrusters Aft, two (2) Bow Thrusters Fwd.

\subsection{Modes of Operations}

The Vessel will be designed with five (5) modes of operations:

(a) DYNPOS AUTRO, Bustie Open

(b) DYNPOS ER, Bustie Open

(c) DYNPOS ER, Bustie Closed

(d) DYNPOS AUTR, Bustie Open

(e) DYNPOS AUTR, Bustie Closed.

During all modes of operations, the minimum quantities of generator sets will be one (1) per switchboard section.

The operational mode of the vessel will be decided on a case by case basis depending on the industrial mission requirements of the End Client User together with input from the Vessel DPO/Master. The total quantities of generating sets required will be based on engine load and prevailing environmental conditions.
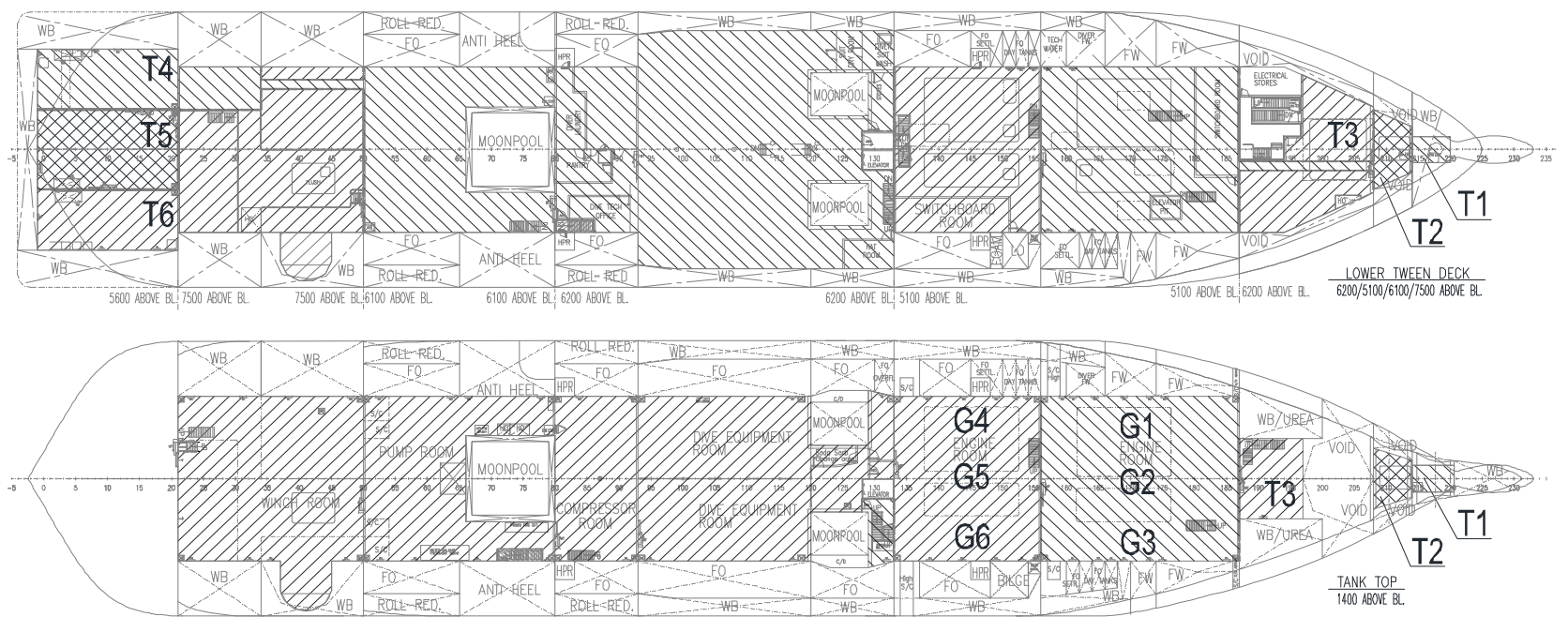

Fig. 1 DP ZONE (part).

Notes: $\square$ DP ZONE 1; $\square$ DP ZONE 2; DP ZONE 3.

Table 2 Technical design for WCFDI.

\begin{tabular}{ll}
\hline Loss of HV Switchboard No. 1 & Loss of HV Switchboard No. 2 \\
\hline One (1) Main HV Switchboard (No. 1) & One (1) Main HV Switchboard (No. 2) \\
Three (3) Generator Sets (G1, G2, G3) & Three (3) Generator Sets (G4, G5, G6) \\
One (1) Azimuth Thruster Aft (T4) & One (1) Azimuth Thruster Aft (T6) \\
One (1) Bow Tunnel Thruster Fwd (T1) & One (1) Bow Retractable Thruster(T3) \\
\hline
\end{tabular}




\section{System Requirements}

\subsection{Sensors}

The requirements of sensors between DYNPOS-ER and DYNPOS-AUTRO are listed in Table 3.

\subsection{Printer}

DYNPOS-AUTRO requires a printer but it can be replaced by a separate data logger.

DYNPOS-ER does not require a printer but a data logger in main DP control system is required. And, this logger should be able to log the alternative DP control system. If not, two loggers are required.

\subsection{Others}

Other systems arrangements, such as main switchboard, bus-tie breaker etc., with no clear different distinction between these two notations, are omitted in this article.

\section{Autonomy of Aux. System}

All generator sets will be installed with autonomous auxiliary supply feeds, thus ensuring the standby start of an off-line generator can be taken into account when considering the DP redundancy consequence analysis performed by the DP system.

These include at least, but not limited to, the following systems: fuel system, lubrication system, fresh water cooling system, ventilation system, compressed air system, combustion air system, exhaust gas system, crank case ventilation, control and power supplies, etc.

\subsection{Fuel System}

There is one (1) FO daily tank for each generator set, three (3) tanks for each E/R, total six (6), and one (1) FO settling tank for each E/R, total two (2) tanks in this vessel. Furthermore, each set equips one (1) set of engine driven FO pump. These configurations insure the autonomy of fuel system for generator set. Fig. 2 is a sketch of fuel system for each generator set.

\subsection{Control and Power Supplies}

Power supplies for the autonomous operation of each engine shall be dual feed from ship AC440V MSB

Table 3 Sensors for DYNPOS-ER and DYNPOS-AUTRO.

\begin{tabular}{|c|c|c|c|c|c|}
\hline \multirow{2}{*}{ Sensors } & \multirow{2}{*}{\multicolumn{2}{|c|}{ DYNPOS-AUTRO }} & \multicolumn{3}{|c|}{ DYNPOS-ER } \\
\hline & & & \multicolumn{3}{|c|}{ Main DP Control system Alternative DP Control system Remark } \\
\hline Position reference systems & 3 & & 3 & 1 & \multirow{4}{*}{$\begin{array}{l}\text { The main DP control } \\
\text { system shall be able } \\
\text { to read all sensors. }\end{array}$} \\
\hline Wind & 3 & 1 of them in backup & 3 & 1 & \\
\hline VRS & 3 & control centre & 3 & 1 & \\
\hline Gyro compass & 3 & & 3 & 1 & \\
\hline
\end{tabular}

DYNPOS-ER requires that all types of sensors should be based on two (2) different working principles separately. When more than one satellite based system is installed, at least one system shall be able to utilize a different satellite system than the others and in addition at least one shall be a dual frequency receiver.

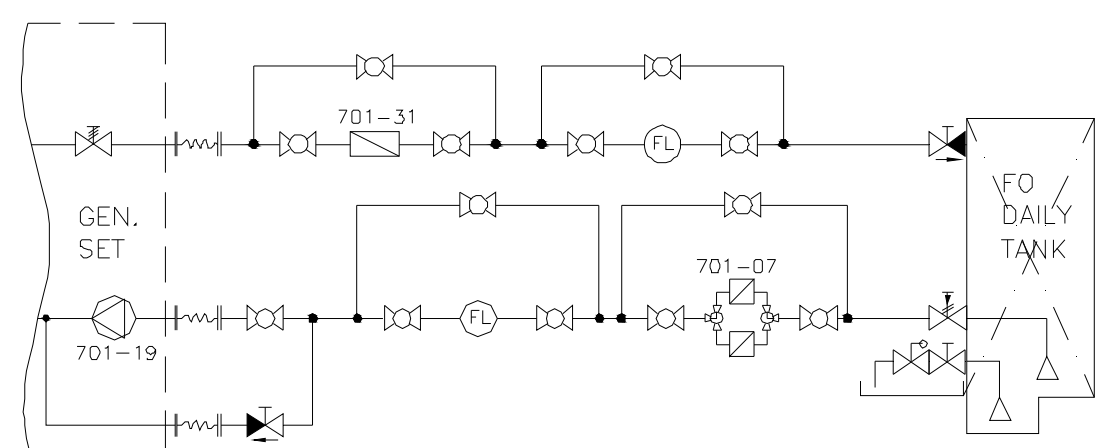

Fig. 2 Sketch of fuel system.

Note: 701-19 is Engine driven pump. 


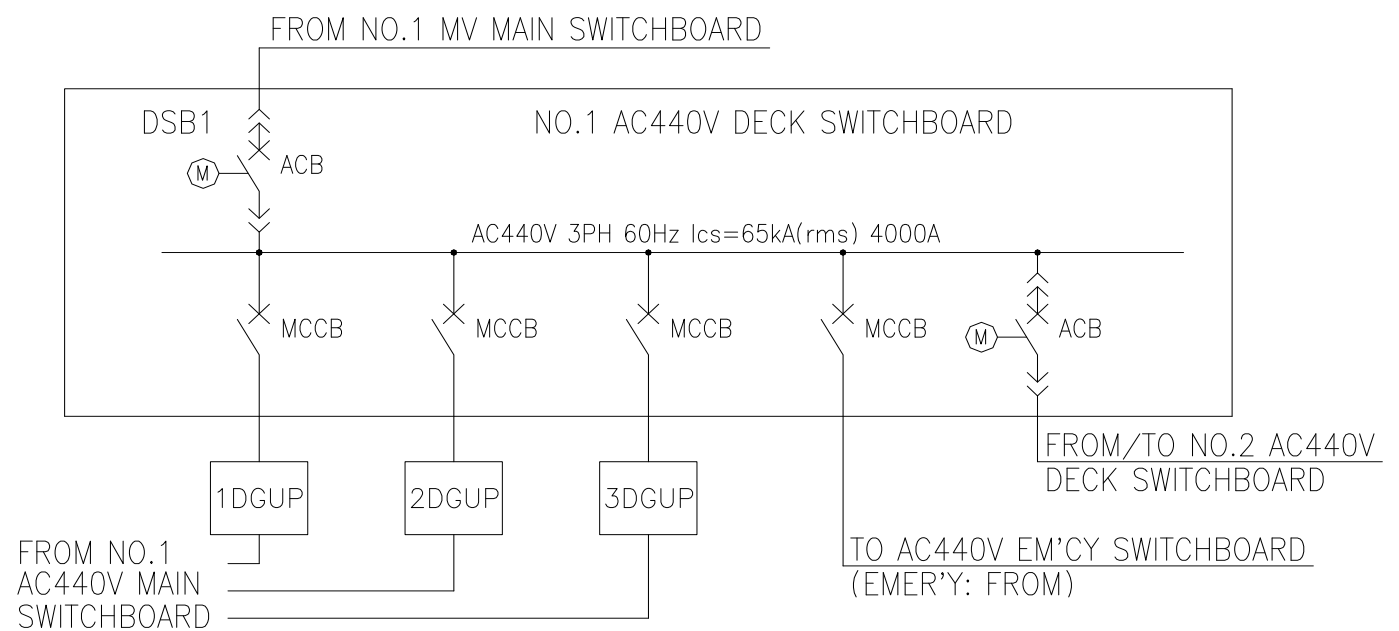

Fig. 3 Sketch of UPS single line diagram.

Note: 1DGUP, 2DGUP, 3DGUP are UPS.

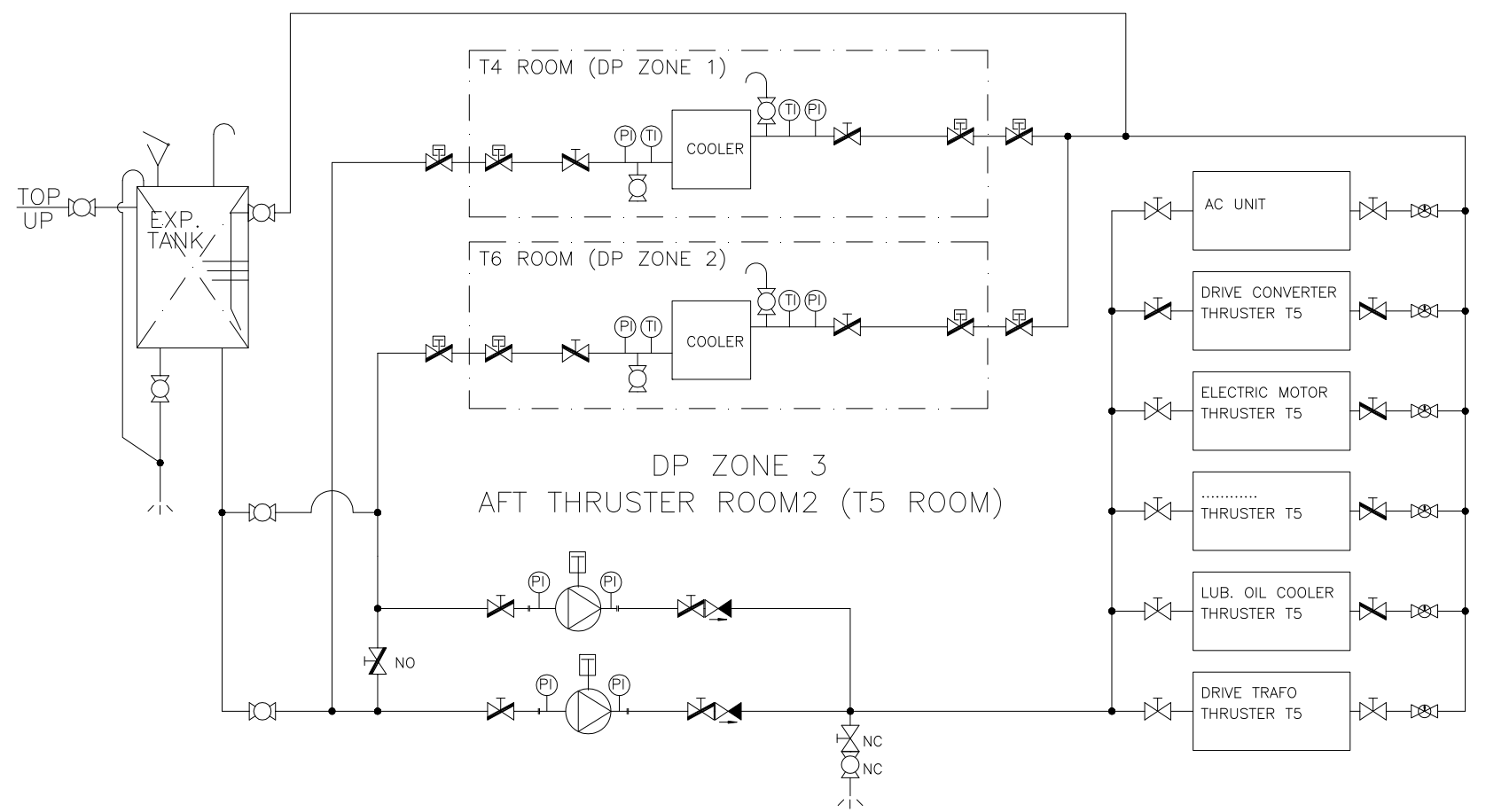

Fig. 4 Autonomous FW cooling system for T5.

and deck AC440V switchboard, via independent UPS systems (one per generator set, Fig. 3 for detail). The six (6) individual UPS's will independently feed governor supply voltage, main engine electronic control unit and sensors, AVR, main MV generator set switchboard panel section and any other deemed necessary by Class.

\subsection{FW Cooling System}

The FW cooling system for equipments in DP ZONE
1 and 2 is same under DYNPOS-AUTRO and DYNPOS-ER Rules. It is not necessary for detail descriptions here. But the systems in DP ZONE 3 are for thruster 2 and 5 and must be autonomous between all thrusters.

Fig. 4 shows the autonomous FW cooling system for thruster 5 (T5). One cooler for T5 is positioned in T4 room (DP ZONE 1) and another in T6 room (DP ZONE 2). Two (2) thrusters can be assured in working condition under any single failure in FW cooling 
system. It is same design for T2.

\subsection{Others}

Regarding to other systems, not detail described, such as lubrication system, compressed air system, etc., they can be designed as per same autonomous principle.

\section{DP Capability Analysis}

This vessel is required to achieve an ern (99, 99, 99, 99) at $\mathrm{T}=7.0 \mathrm{~m}$ according to Class requirements.

\subsection{Power Plants and Thrusters}

Three (3) sets of generator sets (G1, G2, G3) are arranged in No.1 engine room and three (3) sets of generator sets (G4, G5, G6) are arranged in No. 2 engine room. The capacity for each generator set is 2,800 kW. Total six (6) sets are working for this vessel.

The basic info for thrusters is listed in Table 4.

\subsection{Result}

Fig. 5 shows the power consumption for case 1 and Fig. 6 shows the capability envelope for case 4 . The

\section{Table 4 DP Thrusters.}

\begin{tabular}{llllll}
\hline No. & Name & Type & Position & Qty. & Power \\
\hline 1 & Bow Thruster & Tunnel type & Fwd & 2 & $2,680 \mathrm{~kW}$ for each \\
2 & Bow Thruster & Retractable Azimuth type & Fwd & 1 & $2,500 \mathrm{~kW}$ \\
3 & Azimuth Thruster & Nozzle type & Aft & 3 & $3,000 \mathrm{~kW}$ for each \\
\hline
\end{tabular}

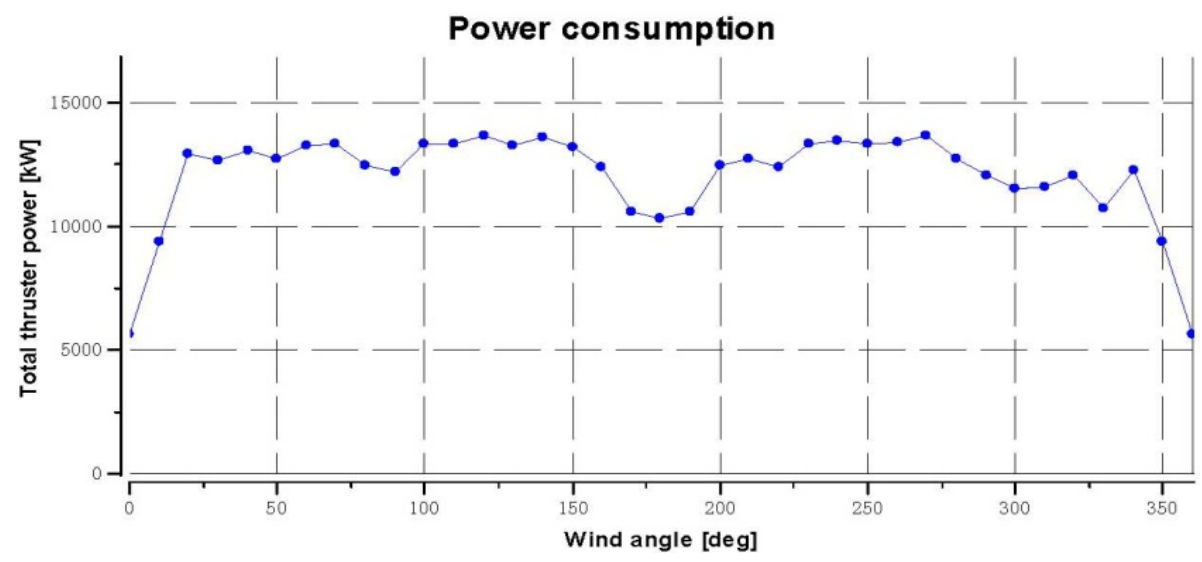

Fig. 5 Power consumption.

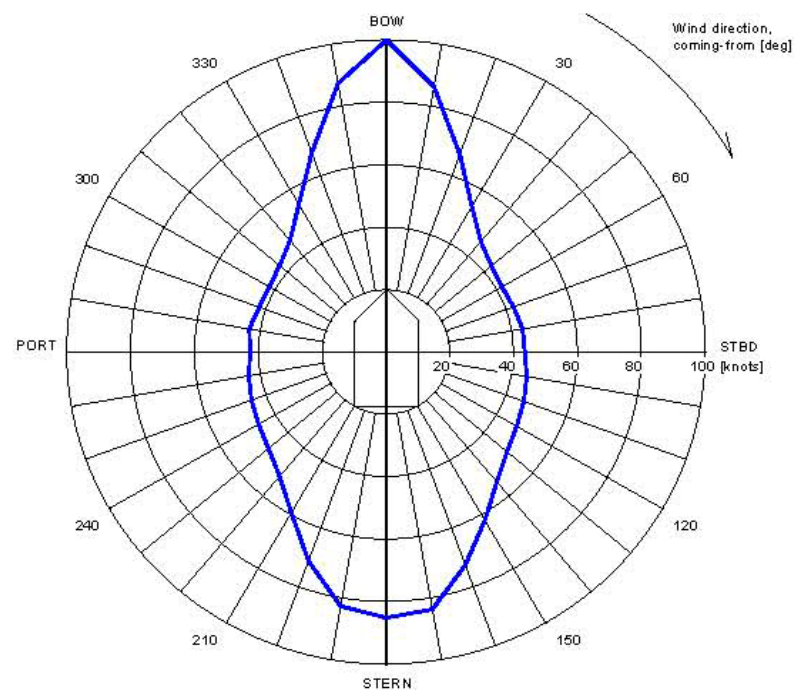

Fig. 6 DP capability envelope. 
results for all four (4) cases can fully achieve the ern.

\section{Conclusions}

DYNPOS-ER is intended for both closed bus-ties and open bus-ties operations. One of the intentions with this notation is to provide a classification standard for DP systems that has high integrity and robustness, as well as being able to utilize the advantages in running with connected power systems [14].

The vessel, with this enhanced notation, can fulfill the requirements for all operational modes, such as diving support, ROV Support and offshore construction, of dynamic positioning. Consideration is made for future operational modes including Pipe/Cable laying, well intervention, wellhead operations and drilling. The FMEA report indicates this case application achieves the requirements of DYNPOS-AUTRO and DYNPOS-ER.

DP enhanced notations provide many additional functions for traditional DP system. These are sophisticated technical for DP at current stage and will be developed ulteriorly along with the development of new technology and diversified needs in the DP market etc. Hope above incomplete descriptions, limited to article space, can be as a reference for other similar projects.

\section{References}

[1] DNV. 2014. "Rules for Classification of Ships." Det Norske Veritas AS.

[2] ABS. 2015. "Rules for Building and Classing, Steel Vessels.” American Bureau of Shipping.

[3] DNV GL. 2016. "DNV GL Rules for Classification: Ships
(RU-SHIP).” DNV GL AS.

[4] IMCA. "Guidance on Failure Modes \& Effects Analysis (FMEAs).” IMCA M 166.

[5] IMCA. "Guidelines for the Design and Operation of Dynamically Positioned Vessels.” IMCA M 103.

[6] IMCA. "Specification for DP Capability Plots.” IMCA M 140.

[7] IMCA. 2004. "Methods for Establishing the Safety and Reliability of Dynamic Positioning Systems.” IMCA M04/04.

[8] IMCA. 2005. “FMEA Management Guide.” IMCA M178.

[9] IMCA. 2010. "A Guide to DP Electrical Power and Control.” IMCA M206.

[10] IMCA. "DP Incident Reports-Various.” IMCA.

[11] IMO. 1994. "Guidelines for Vessels with Dynamic Positioning Systems.” IMO MSC/Circ, 645.

[12] DNV GL. "DNV-RP-D102 FMEA of Redundant Systems." DNV GL AS.

[13] DNV GL. "DNVGL-RP-E306 DP Vessel Design Philosophy Guidelines.” DNV GL AS.

[14] DNV GL. "DNVGL-OTG-10 DP-Classed Vessels with Closed Bus-tie(s).” DNV GL AS.

[15] Liu, Sh.-L., Zhu, J., and Li, X. X. 2013. “Application of Dynamic Positioning System in Ultra Deepwater Drillship.” Ship Engineering 35 (4): 67-70.

[16] Yu, H.-Y., Ma, Ch., and Tong, G. Z. 2014. "Analysis of DP3 Failure Mode Proving Trial Process.” Ship Engineering 36 (1): 123-5.

[17] Ma, C. 2009. "Summary on Dynamic Positioning Vessel Techniques.” Shipbuilding of China 50 (Special Nov.): 52-7.

[18] Wei, W., Li, C. L., and Wang, P. 2009. "Design and Application of Dynamic Positioning DP-3 Countermark on Drilling Platform.” Ship \& Boat August (4): 34-41.

[19] Yang, R.-F. 2013. "Application Analysis of DP3 System of 'Hai Yang Shi You 201'.” Ship Engineering 35 (3): 101-3.

[20] Kong, W., and Yu, Z. H. 2009. "Optimization of Cooling Water Thermal Equilibrium System on Dynamic Positioning Vessels.” Ship\& Boat 3: 48-55. 